\title{
An Overview of Fracture Mechanics with ANSYS
}

\section{Al Emran Ismail ${ }^{1, *}$, Saifulnizan Jamian, KamarulAzhar Kamarudin, Mohd Khir Mohd Nor, Mohd Norihan Ibrahim, Moch. Agus Choiron²}

\author{
${ }^{1}$ Mechanical Failure Prevention and Reliability (MPROVE) Research Center, Faculty of Mechanical and Manufacturing \\ Engineering, Universiti Tun Hussein Onn Malaysia, 86400 Batu Pahat, Johor, MALAYSIA. \\ ${ }^{2}$ Department of Mechanical Engineering, Brawijaya University, Malang, INDONESIA.
}

Received 28 June 2018; accepted 5 August 2018, available online 24 August 2018

\begin{abstract}
This paper reviewed the use of ANSYS finite element program in analyzing the engineering structures containing defects or cracks. It is provided a fracture mechanics module which is capable to model the crack tip efficiently. In studying the cracks in elastic medium, linear elastic fracture mechanics (LEFM) is used where the crack-driving force called stress intensity factor, $J$-integral, energy release rate is provided as indicators of failure. There are three approaches can be used to calculate the stress intensity factors (SIF) such as Displacement Extrapolation Method (DEM) and Interaction Integral Method (IIM). Energy Release Rate (ERR) is calculated using Virtual Crack Closure Technique (VCCT) then it is converted to SIF. Based on the comparison, it is found that DEM, VCCT and $J$-integral techniques produced the SIFs are almost closed to the results obtained from open literature. However, IIM method lead to under estimate the SIFs.
\end{abstract}

Keywords: Fracture Mechanics, ANSYS, Crack, Displacement Extrapolation Method (DEM), J-integral, Interaction Integral Method (IIM), Virtual Crack Closure Method (VCCM), Stress Intensity Factor (SIF).

\section{Introduction}

Finite element analysis is widely used to simulate the behavior of stresses and strains when the structures or components are subjected to mechanical or thermal loading. It is due to the fact that finite element analysis (FEA) offers better and faster preliminary insight of the designed products or structures. One of the capability of FEA is in conducting and solving the problem of fracture mechanics. Courtin et al. [1] presented a work to show the application of $J$-integral in calculating the stress intensity factor (SIF) using ABAQUS finite element software. They compared the values of SIF using both displacement extrapolation and $J$-integral methods. It is found that the SIFs are strongly agreed to each other.

Kuang and Chen [2] used a displacement extrapolation method to investigate the two-dimensional mixed-mode problems. They applied this technique to study the inclined crack due to axial force to obtain modes I and II SIFs and then compared with the SIFs obtained using Barsoum equation [3] using different size of elements around the crack tip. It is found that the results are well-agreed to each other and it is also observed that the differences between SIFs decreased when the elemental size around the crack tip is decreased.

Similarly, Albinmousa et al. [4] also calculated the mode I and II SIFs for single edge notched tension plate under axial tension. In this paper, different slanted angles are used in order to study the effect of the SIFs where the SIFs are determined using displacement extrapolation method available in ANSYS. On the other hand, they are also proposed a flexible model capable to predict the SIFs for different slanted angles. This model is then validated through comparison with existing analytical and numerical solutions as well as experimental results.

Jones and Peng [5] proposed a simple method for calculating the SIFs for cracks emanating from a notch under arbitrary loading. The work is actually initiated by Broek [6] and Smith and Miller [7] based on the depth and the notch radius. The SIFs produced using their expression are well-agreed with the existing results.

Strobl et al. [8] reassessed the formula developed by Newman and Raju [9] using ANSYS finite element software. $J$-integral method with quarter node collapsed crack tip element was used to calculate the SIFs. The SIFs are then compared with the results obtained from [8] and the different are insignificant. Some review on the SIFs can be found in [10-15].

Ismail et al. [16] used $J$-integral analysis available in ANSYS finite element software version 14.0 in studying the surface cracks in round bar under combined mode I loading. Crack model is developed and constructed using ANSYS Parametric Design Language (APDL). The preliminary results are validated with the existing SIFs data and found that the results are well-agreed. In this version, the application of $J$-integral produced a single value of $J$-value and then convert to SIFs. Recently, in ANSYS version 16.0 and above the determination of SIFs using $J$-integral approach can be separated into different mode of failure. This can be realized using interaction integral approach [17] and other can be found in [18-26]. 
Based on the literature survey above, most of the method used world-wide to determine the SIFs for different kinds of crack shapes and geometries is finite element method. It is important task to produce an overview of FEA capabilities especially in analyzing the problems related with fracture mechanics.

\section{Understanding Failure Modes}

Formation of cracks are due to several causes such as metallurgical defect, design discontinuities and at the joint between two materials. Once the crack formed, the behavior of cracks is determined by the direction of forces or moments as in Figure 1. Mode I is an opening mode where the force is perpendicular to the crack faces, mode II is a sliding mode where crack faces slide on each other and the forces are parallel to the crack faces and mode III is a shearing mode where this is mainly due to torsion moments. Griffith firstly introduced the concept of energy release rate, $G$ as in Eq. (1).

$G=\frac{\pi \sigma^{2} a}{E}$

The stress intensity factor, $K$ and the energy release rate, $G$ is then related by Eq. (2).

$$
G=\frac{K^{2}}{E^{\prime}}
$$

where, $a$ is crack length, $\sigma$ is applied stress, $v$ is a Poisson's ratio, $E$ is a modulus of elasticity and $E^{\prime}$ is depend on whether plain stress or strain.
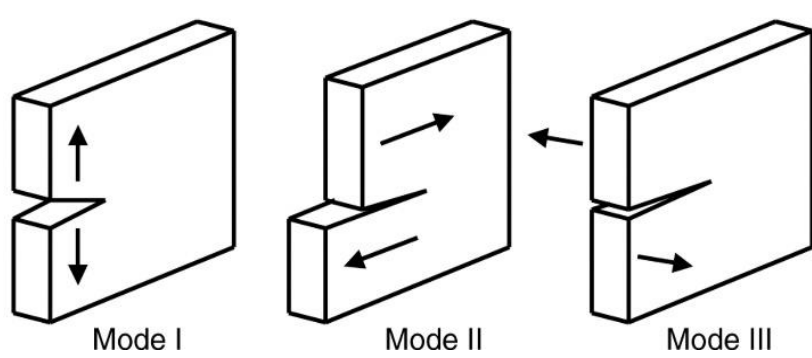

Fig. 1 Type of failure modes, (a) mode I, (b) mode II and (c) mode III.

\subsection{Stress Intensity Factor (SIF)}

Stress intensity factor (SIF) is widely used in analyzing the cracks surrounding by elastic medium. It is called Linear Elastic Fracture Mechanics (LEFM). If the plastic deformation around the crack tip is significant the application of SIF breakdown and it is then replaced with other fracture parameters such as J-integral and other parameters can be found in [27]. In ANSYS, there are two ways to calculate the SIFs, (i) Displacement Extrapolation Method (DEM) and (ii) Interaction Integral Method (IIM). Both methods determine the SIF at the crack tip as in Figure 2. The relationship between stresses and SIFs around the crack tip can be expressed as Eq. (3):

$\sigma_{i j}=-\frac{K_{I}}{\sqrt{r}} f_{i j}(\theta)$
Under the action of mode I loading, the stresses around the crack tip as a follow:

$$
\begin{aligned}
& \sigma_{x}=\frac{K_{I}}{\sqrt{2 \pi r}} \cos \left(\frac{\theta}{2}\right)\left(1-\sin \left(\frac{\theta}{2}\right) \sin \left(\frac{3 \theta}{2}\right)\right) \\
& \sigma_{y}=\frac{K_{I}}{\sqrt{2 \pi r}} \cos \left(\frac{\theta}{2}\right)\left(1+\sin \left(\frac{\theta}{2}\right) \sin \left(\frac{3 \theta}{2}\right)\right) \\
& \sigma_{x y}=\frac{K_{I}}{\sqrt{2 \pi r}} \cos \left(\frac{\theta}{2}\right) \sin \left(\frac{\theta}{2}\right) \sin \left(\frac{3 \theta}{2}\right)
\end{aligned}
$$

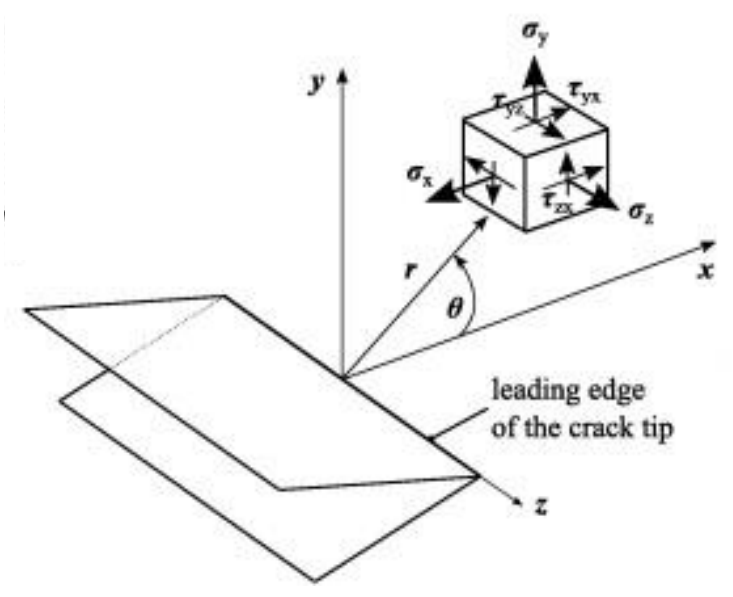

Fig. 2 Schematic diagram of stress distribution ahead of crack front/tip [19].

Since the SIFs are calculated referring to the displacement between two nodes situated along the crack faces around the crack tip as in Figure 3.

$$
\begin{aligned}
& u=\frac{K_{I}}{4 G} \sqrt{\frac{r}{2 \pi}}\left[(2 \chi-1) \cos \left(\frac{\theta}{2}\right)-\cos \left(\frac{3 \theta}{2}\right)\right] \\
& -\frac{K_{I I}}{4 G} \sqrt{\frac{r}{2 \pi}}\left[(2 \chi-1) \sin \left(\frac{\theta}{2}\right)+\sin \left(\frac{3 \theta}{2}\right)\right]
\end{aligned}
$$

$v=\frac{K_{I}}{4 G} \sqrt{\frac{r}{2 \pi}}\left[(2 \chi-1) \sin \left(\frac{\theta}{2}\right)-\sin \left(\frac{3 \theta}{2}\right)\right]$

$-\frac{K_{I I}}{4 G} \sqrt{\frac{r}{2 \pi}}\left[(2 \chi+3) \cos \left(\frac{\theta}{2}\right)+\cos \left(\frac{3 \theta}{2}\right)\right]$

$w=\frac{2 K_{I I I}}{G} \sqrt{\frac{r}{2 \pi}} \sin \left(\frac{\theta}{2}\right)$

where, $u, v$ and $w$ are the displacements in the local Cartesian coordinate. $r$ and $\theta$ are the coordinate in the local cylindrical coordinate system. $G$ and $v$ are the modulus of rigidity and Poisson's ratio, respectively. $K_{i}$ is the stress intensity factor where $i=1,2$ and 3 (mode of loading). The parameter of $\chi$ is depend on the type of plains: 
$\chi=\left\{\begin{array}{l}3-4 v \text { For plain strain } \\ \frac{3-v}{1+v} \text { For plain stress }\end{array}\right.$

\subsection{Interaction Integral Method (IIM)}

Compare with the traditional displacement extrapolation method, Interaction Integral Method offer better accuracy, fewer mesh requirement and ease of use. In DEM, it is required to identify the nodes along the crack faces. However, the node at the crack tip is the only data require to calculate SIF. The $J$-integral, $J(s)$ is evaluated at point $\mathrm{s}$ along the crack front as below (as in Figure 4):

$$
J(s)=\lim _{\Gamma \rightarrow 0} \int_{\Gamma}\left(W \delta_{1 i}-\sigma_{i j} u_{j 1}\right) n_{i} d \Gamma
$$

where $\Gamma(s)$ is an integral contour surrounding the crack tip, $\sigma_{i j}$ is the Cauchy stress, $W$ is the strain energy density, $u_{j l}$ are the components of the displacement gradient tensor and $\delta_{\mathrm{ij}}$ is the Kronecker delta.

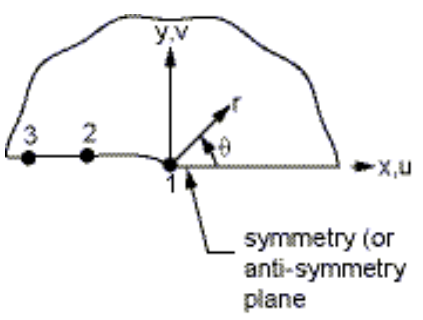

(a)

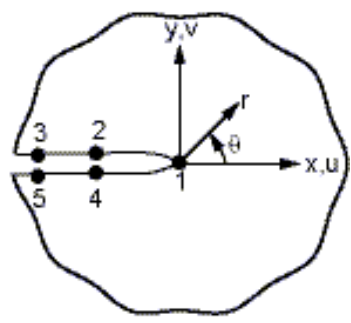

(b)
Fig. 3 Schematic diagram of typical crack face path definition (a) symmetrical face and (b) full faces [17].

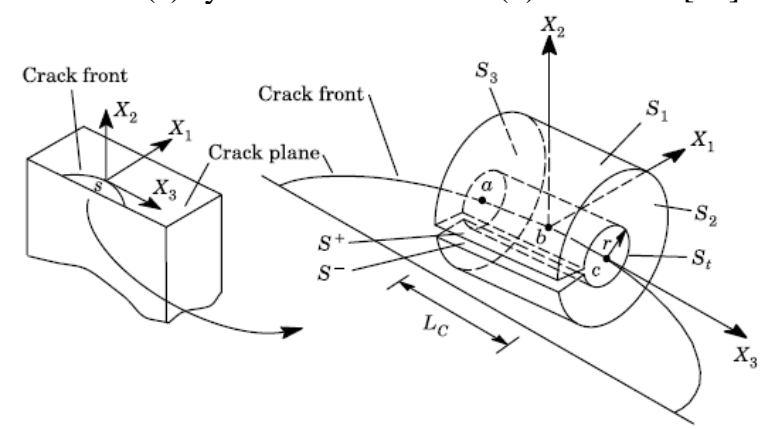

Fig. 4 Area and volume J-integral around the crack front [28].

The area inside the integral contour represents the actual boundary of interest and it is called as the actual field as in Figure 5. If the auxiliary field is superimposed to the actual field, the $J$-integral associated with the combination of both fields, $J_{t}$ can be expressed as below:

$$
J_{\text {total }}=J^{\text {actual }}+J^{\text {aux }}+I
$$

where $J_{a c t}$ and $J_{\text {aux }}$ are the $J$-integral values obtained actual and auxiliary fields, respectively. The interaction integral, $I$ is also known as $M$-integral can be expressed as:

$$
I(s)=\lim _{\Gamma \rightarrow 0} \int_{\Gamma}\left(\sigma_{i k} \varepsilon_{i k}^{a u x} \delta_{l j}-\sigma_{i k} \varepsilon_{i l}^{a u x}-u_{i l} \sigma_{i j}^{a u x}\right) n_{j} d \Gamma
$$

where $\sigma_{i j}^{a u x}, \varepsilon_{i k}^{a u x}$ and $u_{i l}$ are the auxiliary stress, strain and displacement fields. There auxiliary parameters are firstly defined by setting up their local coordinate system originated at point $\mathrm{s}$ on the crack front. The $x^{\prime}{ }_{1}$ axis is aligned with the vector $c$, the $x^{\prime}{ }_{2}$ axis is aligned in the $b$ direction and $x_{3}{ }_{3}$ is aligned parallel to the vector $T$.

The auxiliary stress field is defined as:

$\sigma_{i j}^{a u x}=\frac{K_{I}^{a u x}}{\sqrt{2 \pi r}} f_{i j}^{I}(\theta)+\frac{K_{I I}^{a u x}}{\sqrt{2 \pi r}} f_{i j}^{I I}(\theta)$

$\sigma_{13}^{a u x}=\frac{K_{I I I}^{a u x}}{\sqrt{2 \pi r}} f_{i j}^{I I I}(\theta)$

$\sigma_{33}=v\left(\sigma_{11}^{a u x}+\sigma_{22}^{a u x}\right)$

where $K_{I}^{\text {aux }}, K_{I I}^{\text {aux }}$ and $K_{I I I}^{\text {aux }}$ are the SIFs associated with the auxiliary fields and $f_{i}(\theta)$ is associated with the angular function of near tip fields.

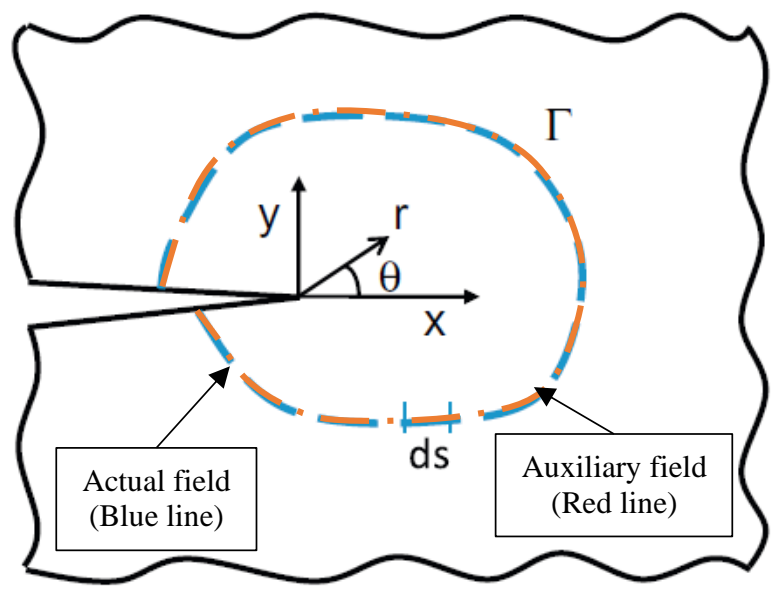

Fig. 5 Contour around the crack tip.

The auxiliary displacement components are defined as below:

$u_{1}^{a u x}=\frac{1}{8 \mu} \sqrt{\frac{2 r}{\pi}}\left[K_{I}^{a u x} f^{I}(\theta)+K_{I I}^{a u x} f^{I I}(\theta)\right]$

$u_{2}^{a u x}=\frac{1}{8 \mu} \sqrt{\frac{2 r}{\pi}}\left[K_{I}^{a u x} g^{I}(\theta)+K_{I I}^{a u x} g^{I I}(\theta)\right]$

$u_{3}^{a u x}=\frac{1}{\mu} \sqrt{\frac{2 r}{\pi}}\left[K_{I I I}^{a u x} g^{I I I}(\theta)\right]$

where $\mu$ is the shear modulus. The auxiliary strain fields are dined as below:

$\varepsilon_{i j}^{a u x}=\frac{1}{2}\left(u_{i j}^{a u x}+u_{j i}^{a u x}\right)$ 
$\varepsilon_{i 3}^{a u x}=\frac{1}{2} \frac{\partial u_{3}^{a u x}}{\partial x_{1}}$

$\varepsilon_{23}^{a u x}=\frac{1}{2} \frac{\partial u_{3}^{a u x}}{\partial x_{2}}$

$\varepsilon_{33}^{a u x}=0$

When the actual and auxiliary fields of stress intensity factors are substituted in the interaction integral, the expression below can be obtained:

$I(s)=\frac{2\left(1-v^{2}\right)}{E}\left(K_{I} K_{I}^{a u x}+K_{I I} K_{I I}^{a u x}\right)+\frac{1}{\mu} K_{I I I} K_{I I I}^{a u x}$

Therefore, the actual stress intensity factors can be determined by evaluating such interaction integral. For an example, mode I SIF can be found by setting $K_{I}^{a u x}=1$ and other auxiliary SIFs are kept zero. Thus, mode I SIF is:

$$
K_{I}(s)=\frac{E}{2\left(1-v^{2}\right)} I(s)
$$

\subsection{J-integral}

The above two fracture parameters discussed above is only applicable when the insignificant amount of plasticity around the crack tip is observed. However, when the plasticity is large the application of SIF is breakdown and unusable. One of the advantages of using $J$-integral as a fracture parameter is it can be used both conditions for elastic and inelastic regions. $J$-integral is determined firstly by constructing the contour around the crack tip. Several number of contours must be used in order to ensure that the value of $J$-integral converged. The evaluation of $J$-integral is based on the domain integral method which is firstly derived by Shih and Moran [29]. There are two types of domain integral for area and volume integrations where it is better and accurate than the contour or surface integral. For the two-dimensional problem, the area domain integral is defined as:

$$
J=\int_{A}\left[\sigma_{i j} \frac{\partial u_{j}}{\partial x_{1}}-w \delta_{1 i}\right] \frac{\partial q}{\partial x_{i}} d A
$$

where $\sigma_{i j}$ is the stress tensor, $u_{j}$ is the displacement vector, $\mathrm{w}$ is the strain energy density, $\delta_{i j}$ is the Kronecker delta, $x_{i}$ is the coordinate axis and $q$ is referred to as the crack extension vector. For the three-dimensional problem, volume domain integral is used around the crack tip. In ANSYS [17], command CINT is used to perform the calculation of $J$-integral.

\subsection{Virtual Crack Closure Technique (VCCT)}

The virtual Crack Closure Technique (VCCT) is based on the energy balance which is firstly proposed by Irwin. The SIF, $K$ is calculated according to the expression below:

$G_{i}=\frac{K_{i}^{2}}{E} \beta$ where $G$ is energy release rate and $i=1,2$ and 3 depending on the mode of loading. $E$ is a modulus of elasticity, $v$ is a Poisson's ratio and $\beta=1$ for plane stress and $\beta=1-\nu 2$ for plain strain. The energy release rate is based on the assumption that the energy release in the process of crack expansion is equal to the work require to close the crack to its original state as the crack extends by a small amount of $\Delta c$ and it is expressed as:

$W=\frac{1}{2} \int_{0}^{\Delta c} u(r) \sigma(r-\Delta c) d r$

where, $u$ is the relative displacement, $\sigma$ is the stress, $r$ is the distance from the crack tip and $\Delta c$ is the change in virtual crack length as in Figure 6. Then, the energy release rate can be derived as:

$G=\lim _{\Delta c \rightarrow 0} \frac{W}{\Delta c}=\lim _{\Delta c \rightarrow 0} \frac{1}{2 \Delta c} \int_{0}^{\Delta c} u(r) \sigma(r-\Delta c) d r$

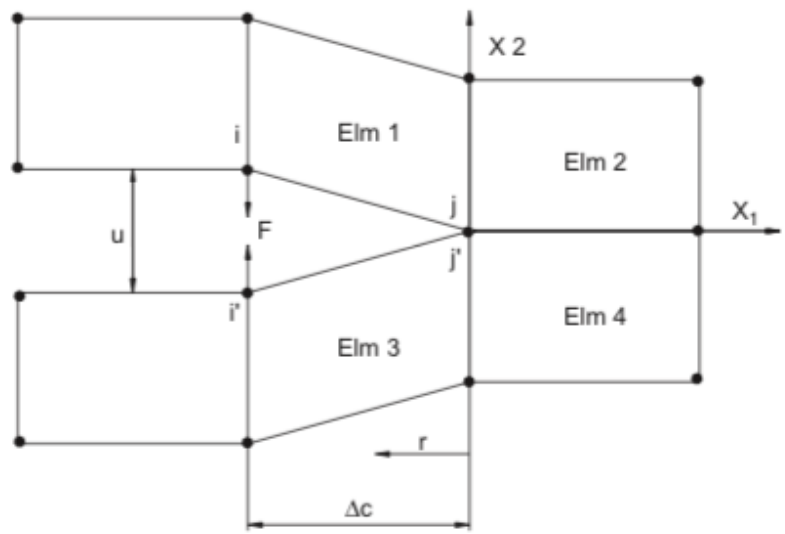

Fig. 6 Two-dimensional finite element model in the vicinity of a crack tip before the virtual closure.

In ANSYS, for the case of two-dimensional model as in Figure 6, the energy release rate for mode I, $G_{I}$ and mode II, $G_{I I}$ are calculated using the expression below, respectively:

$G_{I}=-\frac{1}{2 \Delta a} R_{Y} \Delta v$

$G_{I I}=-\frac{1}{2 \Delta a} R_{Y} \Delta u$

where, $\Delta u$ and $\Delta v$ are the relative displacement between the upper and bottom nodes of the crack faces, respectively. While $R_{x}$ and $R_{y}$ are the reaction forces at the crack tip in $x$ - and $y$-axes and $\Delta a$ is the crack extension. For the case of three-dimensional, an additional $z$-axis is required used to calculate the energy release rate for mode III, $G_{I I I}$ expressed as below:

$G_{I I I}=-\frac{1}{2 \Delta a} R_{Z} \Delta w$ 
For this case, $\Delta a$ is based on the area crack extension as revealed in Figure 7.

\section{Numerical Example}

In the present study, a central crack in a plain strain plate is used and modelled using ANSYS Parametric Design Language (APDL) in ANSYS finite element program. Figure 8 shows two type of cracked plates such as single-edge and central-crack in plates. Since the cracks are symmetrical, only half and quarter crack models are used and constructed in ANSYS, respectively. Before constructing finite element model, it is firstly assumed that there are two type of plates, $H / W=0.4$ (rectangularshaped) and $H / W=1.0$ (square-shaped). Details of crack length are tabulated in Tables 1 and 2.

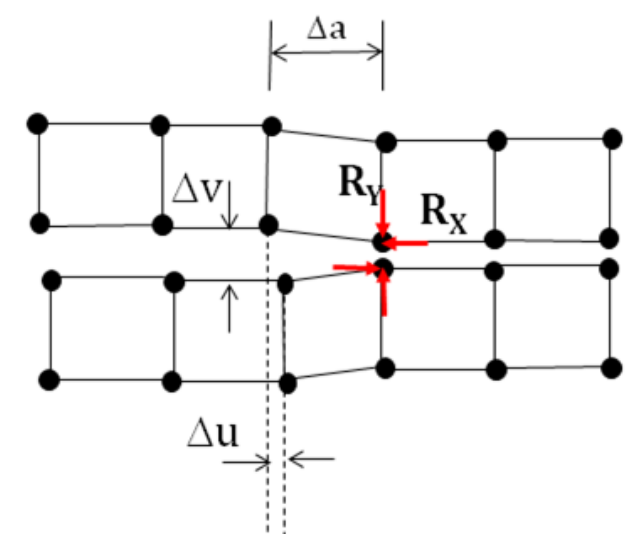

(a)

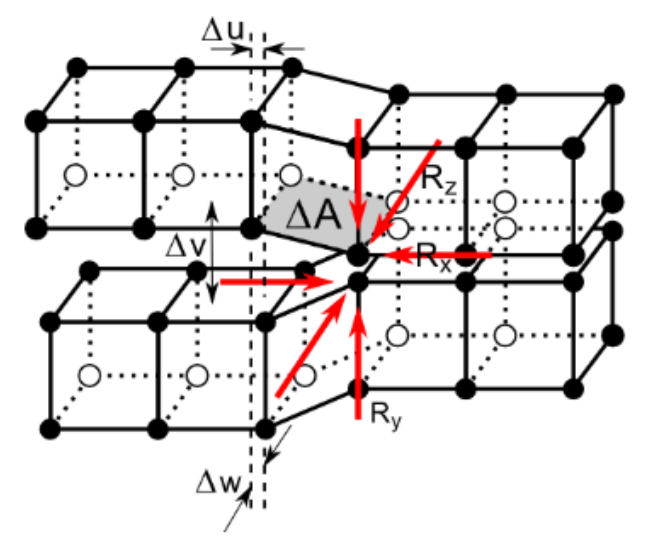

(b)

Fig. 7 Schematic of finite element model for (a) twodimensional and (b) three-dimensional [17].

Table 1 . Geometry and crack sizes of $H / W=0.4$.

\begin{tabular}{ccccc}
\hline$a / W$ & $W$ & $a$ & $H / W$ & $H$ \\
\hline 0.1 & 50 & 5 & 0.4 & 20 \\
0.2 & 50 & 10 & 0.4 & 20 \\
0.3 & 50 & 15 & 0.4 & 20 \\
0.4 & 50 & 20 & 0.4 & 20 \\
0.5 & 50 & 25 & 0.4 & 20 \\
0.6 & 50 & 30 & 0.4 & 20 \\
0.7 & 50 & 35 & 0.4 & 20 \\
\hline
\end{tabular}

Table 2. Geometry and crack sizes of $H / W=1.0$.

\begin{tabular}{ccccc}
\hline$a / W$ & $W$ & $a$ & $H / W$ & $H$ \\
\hline 0.1 & 50 & 5 & 1.0 & 50 \\
0.2 & 50 & 10 & 1.0 & 50 \\
0.3 & 50 & 15 & 1.0 & 50 \\
0.4 & 50 & 20 & 1.0 & 50 \\
0.5 & 50 & 25 & 1.0 & 50 \\
0.6 & 50 & 30 & 1.0 & 50 \\
0.7 & 50 & 35 & 1.0 & 50 \\
\hline
\end{tabular}

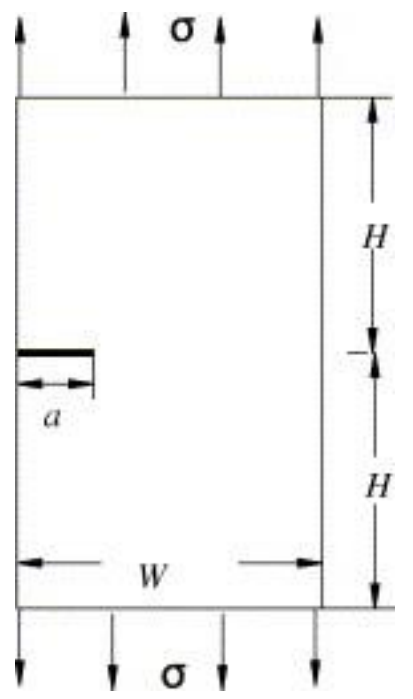

(a)

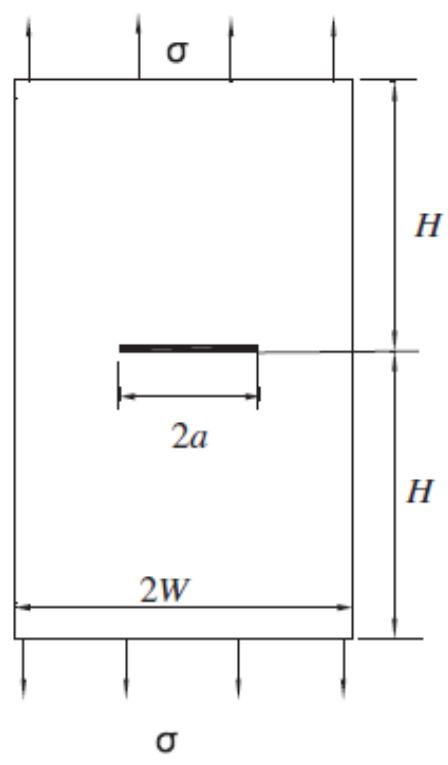

(b)

Fig. 8 Rectangular plain strain plate with (a) single-edge crack and (b) central cracks [29].

There are many ways to construct the plate with crack. One of the simplest method is to identify the important coordinates (in APDL command it is called KEYPOINT or $\mathrm{K}$ ) as in Figure $\mathrm{y}$ as in Table 3. Once the coordinates are 
formed and then create the area (APDL code for AREA is A) based on such coordinates. The line 1-2 represents the crack face.

Table 3. Key points used to construct the model.

\begin{tabular}{cccc}
\hline \multirow{2}{*}{ Key Points } & \multicolumn{3}{c}{ Coordinates } \\
\cline { 2 - 4 } & $x$ & $y$ & $z$ \\
\hline 1 & 0 & 0 & 0 \\
2 & 5 & 0 & 0 \\
3 & 50 & 0 & 0 \\
4 & 50 & 20 & 0 \\
5 & 0 & 20 & 0 \\
\hline
\end{tabular}

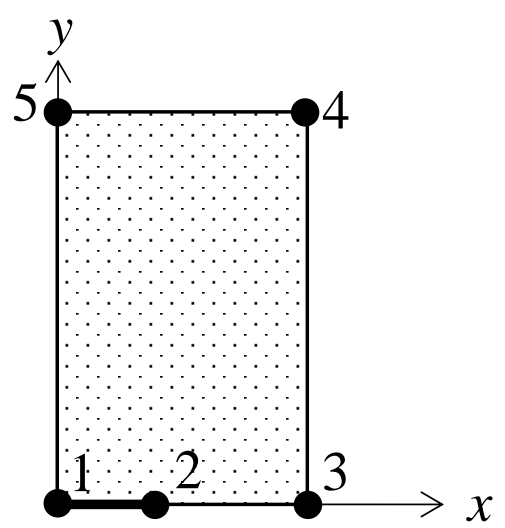

Figure 9. Single edge / central crack model.

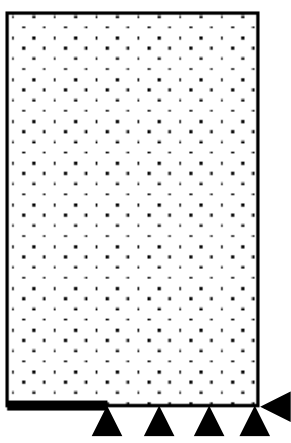

Figure 10. (a) Half-model of single edge crack and (b) Quarter-model of central crack.

Since, there are two types of crack. Figure 8 can be used for both crack configurations and the only difference is boundary condition. Figure 9 shows the boundary condition used to characterize different crack configurations. Figure 10 shows the half-model for a single-edge crack. The bottom line is constrained in ydirection except for the line of crack face. The model is also constrained at the bottom-right point in $x$-direction to prevent body rotation. It is also revealed the finite element mesh used to model the plate and singular element is used to model the crack tip. It is important to simulate the square-root of stresses and strains around the tip especially when DEM is used. If VCCT is used, singular element around the tip is not necessary.

For a central crack on a quarter model is used in order to reduce the number of elements/nodes and therefore reduce the computational time and cost. For all cases of crack, upward pressure is applied directly to the upper lines. Once the construction of model is completed, mechanical properties such as modulus of elasticity and Poisson's ratio are assigned to the model and the model is meshed with suitable two-dimensional plain strain element for an example of Quadrilateral element or PLANE183.

For validation purposes, the SIFs are determined using a displacement extrapolation method. In order to eliminate the effect of sizes, the SIFs are normalized as below:

$F=\frac{K}{\sigma \sqrt{\pi a}}$

where, $F$ is a normalized SIF, $K$ is a SIF, $\sigma$ is an applied stress and $a$ is a crack length. Figure 11 reveals the stress distribution when uniaxial stress is applied to the plate. Figure 12 shows that the validations between the present and the existing finite element models. It is also observed that both models are well-agreed to each other and it can be used for further works.

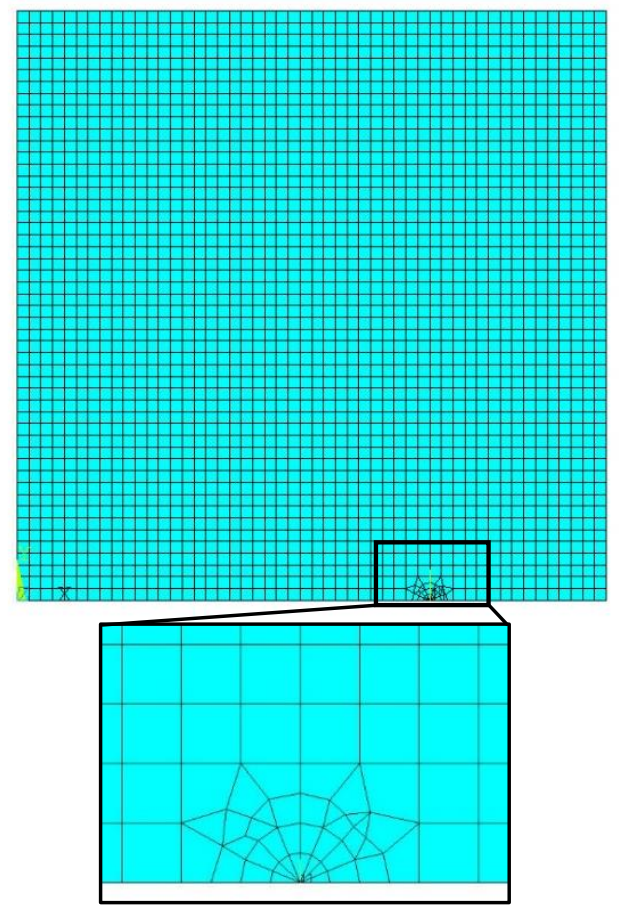

Fig. 11 Finite element model of single edge crack under tension stress. 


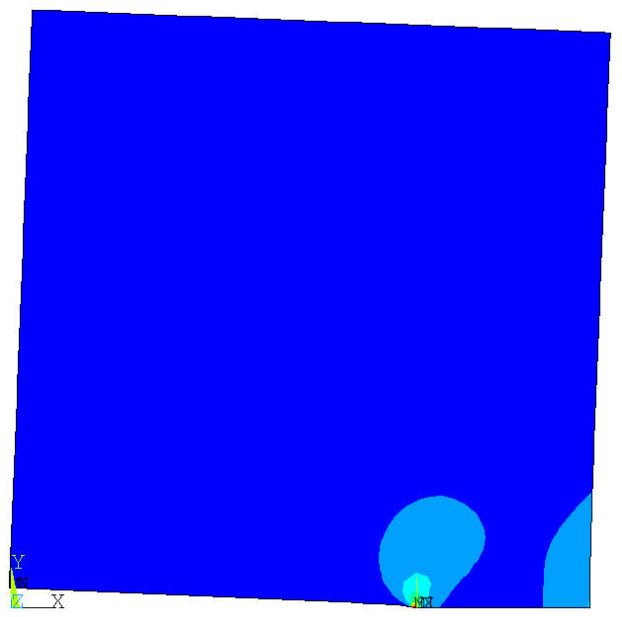

Fig. 12 Deformed single-edge crack under axial force.

\section{Comparative Study}

In this section, four crack driving forces are determined and compared where linear elastic deformation are strictly considered. For the sake of comparison, all the crack driving forces are converted to SIFs using the expression below for plain strain condition especially for $J$-integral and Virtual Crack Closure Technique (VCCT):

$$
\begin{aligned}
& K_{I}=\sqrt{\frac{G_{I} E}{1-v^{2}}} \\
& K_{I}=\sqrt{\frac{J_{I} E}{1-v^{2}}}
\end{aligned}
$$

where $G$ is an energy release rate obtained using VCCT while $J$ is a $J$ values obtained using $J$-integral method. An elastic deformation is characterized considering the modulus of elasticity, $E$ and Poisson's ratio, $v$. For other methods for examples displacement extrapolation method and interaction integral method, the stress intensity factors can be extracted directly and therefore there is no need for conversions. For comparison purposes, square plain strain plate $(H / W=1.0)$ is considered.

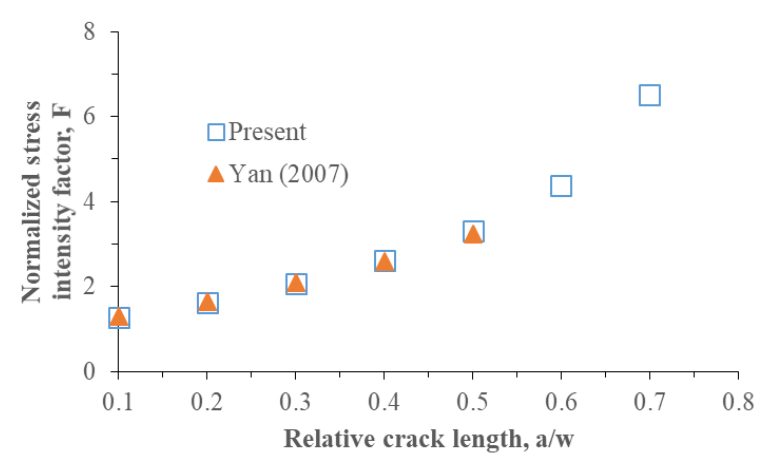

(a)

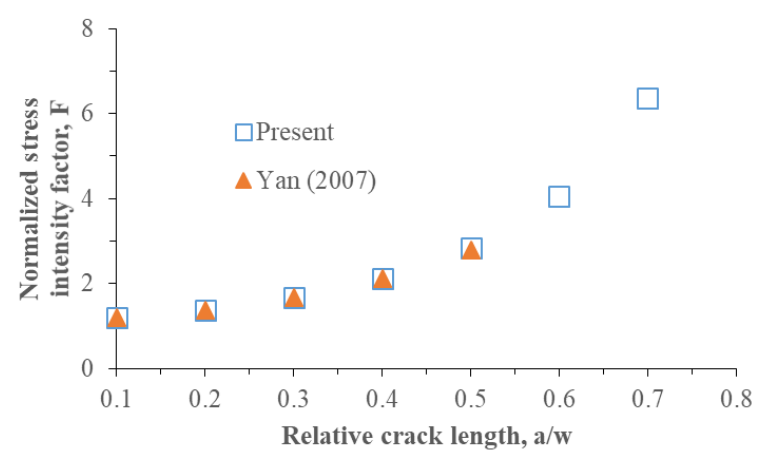

(b)

Fig. 13. Validation of finite element model of different plate aspect ratios, (a) $H / W=0.4$ and (b) $H / W=1.0$ of single edge crack.

Fig. 13 shows the comparison between four different methods available in ANSYS can be used to calculate the SIFs. All results are then compared with the data obtained from Yan [30]. It is observed that both the results obtained using DEM and VCCT are almost closed to the Yan [30]. On the other hand, IIM method seemed leading to underestimate the SIFs since the values showed significant fluctuations. The details of SIF values are tabulate in Table 4.

\section{Summary}

Based on the numerical simulation using ANSYS finite element program through the use of ANSYS Parametric Design Language (APDL), successful fracture mechanics analysis is conducted to study the plain strain plate contained crack. In ANSYS, there are several techniques can be used to calculate the stress intensity factor (SIF) such as Displacement Extrapolation Method (DEM), J-Integral, Interaction Integral Method and Energy Release Rate Method. The last three methods can be utilized to extract the SIF as long as the analysis remain within the elastic limit. On the other hand, such methods are not necessary to implement singular element around the crack tip except for the case of displacement extrapolation method.

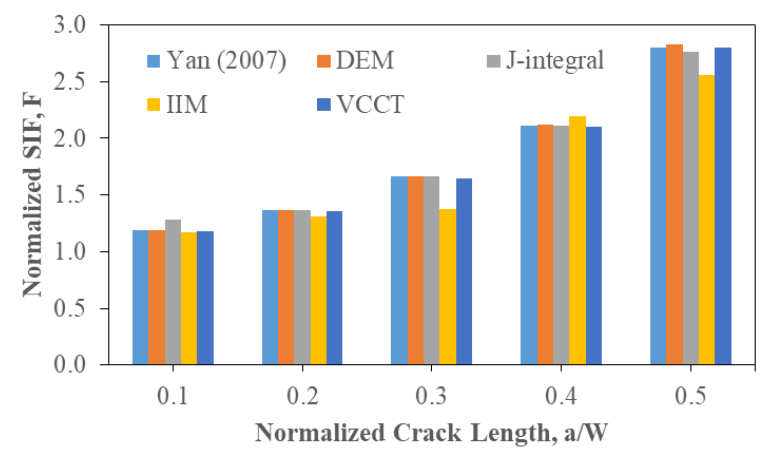

Fig. 14. Comparison between four techniques can be used to calculate the stress intensity factors.

Table 4 List of SIFs values using different techniques available in ANSYS. 


\begin{tabular}{cccccc}
\hline $\mathrm{a} / \mathrm{w}$ & Yan (2007) & DEM & J-integral & IIM & VCCT \\
\hline 0.1 & 1.1880 & 1.1916 & 1.2829 & 1.1682 & 1.1768 \\
0.2 & 1.3695 & 1.3707 & 1.3706 & 1.3120 & 1.3578 \\
0.3 & 1.6631 & 1.6642 & 1.6609 & 1.3737 & 1.6496 \\
0.4 & 2.1096 & 2.1166 & 2.1137 & 2.1978 & 2.0978 \\
0.5 & 2.7962 & 2.8305 & 2.7590 & 2.5614 & 2.8038 \\
\hline
\end{tabular}

\section{Acknowledgement}

Authors acknowledge Kementerian Pengajian Tinggi (KPT) for sponsoring this paper through Fundamental Research Grant Scheme (FRGS) 2016, Vot. 1592.

\section{References}

[1] Courtin, S., Gardin, C., Bezine, G., and Ben Hadj Hamouda H. Advantages of the J-integral approach for calculating stress intensity factors when using the commercial finite element software ABAQUS. Engineering Fracture Mechanics, Volume 72 (2005), pp. 2174-2185.

[2] Kuang J.H., and Chen, L.S. A displacement extrapolation method for two-dimensional mixedmode crack problems. Engineering Fracture Mechanics, Volume 46 (1993), pp. 735-741.

[3] Barsoum R.S. On the use of isoparametric finite elements in linear fracture mechanics. International Journal for Numerical Methods in Engineering, Volume 10 (1976), pp. 25073.

[4] Albinmousa, J., Merah, N., and Khan, S.M.A. A model for calculating geometry factors for a mixedmode I-II single edge notched tension specimen. Engineering Fracture Mechanics, Volume 78 (2011), pp. 3300-3307.

[5] Jones, R. and Peng, D. A simple method for computing the stress intensity factors for cracks at notches. Engineering Failure Analysis, Volume 9 (2002), pp. 683-702.

[6] Broek, D. The propagation of fatigue cracks emanating from holes. National Aerospace Laboratory, Report NLR TR 72134 U, Amsterdam, 1972.

[7] Smith, R.A, and Miller, K.J. Fatigue cracks at notches. International Journal of Mechanical Sciences, Volume 19 (1977), pp. 11-22.

[8] Strobl, S., Supancic, P., Lube, T., and Danzer, R. Surface crack in tension or in bending - A reassessment of the Newman and Raju formula in respect to fracture toughness measurement in brittle materials. Journal of the European Ceramic Society, Volume 8 (2012), pp. 1491-1501.

[9] Newman, J.C., and Raju, I.S. An empirical stress intensity factor equation for the surface crack. Engineering Fracture Mechanics, Volume 15 (1981), pp. 185-192.
[10] Murakami, Y. Stress intensity factors handbook. Pergamon Press, Oxford (1987-2001).

[11]Raju, I.S., and Newman, J.C. Improved stressintensity factors for semi-elliptical surface cracks in finite-thickness plates. NASA Report TM-X-72825; 1977.

[12] Newman, J.C., and Raju, I.S. Analysis of srface cracks in finite plates under tension or bending loads. NASA. Report TP-1578; 1979.

[13] Isida, M., Noguchi, H., and Yoshida, T. Tension and bending of finite thickness plates with a semi-elliptical surface crack. International Journal of Fracture, Volume 26 (1984), pp. 157-188.

[14] McGowan, J.J. A critical evaluation of numerical solutions to the benchmark surface flaw problem. Society for Experimental Stress Analysis, Westport (1980).

[15] Newman J.C. A review and assessment of the stress intensity factor for surface cracks. J.B. Chang (Ed.), Part-through crack fatigue life prediction, ASTM STP 687, American Society for Testing and Materials (1979).

[16] Ismail, A.E., Ariffin, A.K., Abdullah, S., and Ghazali, M.J. Finite element analysis of J-integral for surface cracks in round bars under combined mode I loading. International Journal of Integrated Engineering, Volume 9 (2017), pp. 1-8.

[17] ANSYS Manual Version 16.0.

[18] Ismail, A.E., Ariffin, A.K., Abdullah, S., and Ghazali, M.J. Stress intensity factors under combined tension and torsion loadings. Indian Journal of Engineering and Materials Sciences, Volume 19 (2012), pp. 5-16.

[19] Ismail, A.E., Ariffin, A.K., Abdullah, S., Ghazali, M.J., Abdulrazzaq, M., and Daud, R. Stress intensity factors under combined bending and torsion moments. Journal of Zhejiang University: Science A, Volume 13 (2012), pp. 1-8.

[20] Ismail, A.E., Ariffin, A.K., Abdullah, S., Ghazali, M.J., and Daud, R. Mode III stress intensity factors of surface crack in round bars. Advanced Materials Research, Volume 214 (2011). pp. 192-196.

[21] Ismail, A.E., Ariffin, A.K., Abdullah, S., and Ghazali, M.J. tress intensity factors for surface cracks in round bars under combined bending and torsion loadings. International Review of Mechanical Engineering, Volume 4 (2010), pp. 827-832.

[22] Ismail, A.E. Multiple crack interactions in Bi-Material plates under mode I tension loading. Applied Mechanics and Materials, Volume 629 (2014), pp. 57-61.

[23] Ismail, A.E., Tobi, A.L.M., and Nor, N.H.M. Stress intensity factors of slanted cracks in round bars subjected to mode I tension loading. AIP Conference Proceedings, Volume 1660 (2015), 070027.

[24] Ismail, A.E., Ariffin, A.K., Abdullah, S., and Ghazali, M.J. Ungkapan kamiran-J retak permukaan pada bar silinder padu kenaan beban ragam I. Jurnal Teknologi (Sciences and Engineering), Volume 68 (2014), pp. 717. 
[25] Ismail, A.E. Development of J-integral prediction model for surface cracks in round bars under combined loadings. Applied Mechanics and Materials, Volume 315 (2013), pp. 665-669

[26] Ismail, A.E., Ariffin, A.K., Abdullah, S., and Ghazali, M.J. Effect of crack faces opening mechanisms on the combined stress intensity factors under bending and torsion moments. International Review on Modelling and Simulations, Volume 4 (2011), pp. 3232-3238

[27]Zhu, X.K., and Joyce, J.A. Review of fracture toughness (G, K, J, CTOD, CTOA) testing and standardization. Engineering Fracture Mechanics, Volume 85 (2012), pp. 1-46.
[28] Matthew, C.W., Glaucio, H.P., Rober, H.D. Jr. Interaction integral procedure for 3-D curved cracks including surface tractions. Engineering Fracture Mechanics, Volume 72 (2005), pp. 1635-1663.

[29] Shih, C.F., Moran, B., and Nakamura, T. Energy release rate along a three-dimensional crack front in thermally stresses body. International Journal of Fracture, Volume 30 (1986), pp.79-102.

[30] Xiangqiao Yan. Rectangular tensile sheet with single edge crack or edge half-circular-hole crack, Engineering Failure Analysis, Volume 14(7) (2007) 1406-1410. 